\title{
The ideas of the young V. O. Klyuchevsky \\ on the goals of personal development and the progress of Russian society in the 1860s.
}

\section{A. Tsoy ${ }^{1}$}

${ }^{1}$ Yaroslavl State Pedagogical University named after K.D. Ushinsky, 108/1 Respublikanskaya str., Yaroslavl 150000, Russian Federation

DOI: $10.18255 / 1996-5648-2021-4-488-497$

Research article

Full text in Russian

The article gives an interpretation of the ideas of the young V.O. Klyuchevsky about the peculiarities of the ideological search of young people and the direction of development of Russian society in the sixties of the XIX century. The novelty of the research lies in the attempt to comprehend the problem of perception of V. O. Klyuchevsky himself was one of the representatives of the younger generation of the 1860s, in assessing his ideas about the ideological and value foundations of the activities of the individual and society in Russia during the era of the Great Reforms. The main source of work is the diaries of V.O. Klyuchevsky. The study was carried out in line with modern methodological approaches, which involve the study of the ideological and moral foundations of the culture of the individual in the context of the historical era.

Keywords: V. O. Klyuchevsky; history of Russia; "Great reforms"; 1860s; Russian intellectuals; personal freedom; diaries of V. O. Klyuchevsky

INFORMATION ABOUT AUTHORS

Tsoi, Igor A. | E-mail: tsoyigo@mail.ru

Cand. Sc. degree seeking applicant 


\title{
Идеи молодого В. О. Ключевского \\ о целях развития личности \\ и российского общества в 1860-е годы
}

\author{
И. А. Цой ${ }^{1}$
}

${ }^{1}$ Ярославский государственный педагогический университет им. К. Д. Ушинского, Республиканская улица, дом 108/1, Ярославль, 150000, Российская Федерация

DOI: 10.18255/1996-5648-2021-4-488-497

УдК 94 (47)

Научная статья

Полный текст на русском языке

В статье дана интерпретация идей молодого В. О. Ключевского об особенностях идейного поиска молодых людей и направления развития русского общества в шестидесятые годы XIX в. Новизна исследования заключается в попытке осмысления проблемы восприятия В. О. Ключевским себя одним из представителей молодого поколения 1860-х годов, в оценке его представлений об идейно-ценностных основах деятельности личности и общества в России эпохи Великих реформ. Основной источник работы - дневники В. О. Ключевского. Исследование выполнено в русле современных методологических подходов, предполагающих изучение идейно-нравственных основ культуры личности в контексте исторической эпохи.

Ключевые слова: В. О. Ключевский; история России; «Великие реформы»; 1860-е годы; русские интеллектуалы; свобода личности; дневники В. О. Ключевского

ИНФОРМАЦИЯ ОБ АВТОРАХ

Цой, Игорь Александрович $\mid$ E-mail: tsoyigo@mail.ru

Соискатель

«Новые люди», заявившие о себе в 1860-е гг., надеялись на преобразование России на основе идеи свободы личности. Термины «новые люди», «наше поколение», «люди шестидесятых годов», «шестидесятники» - синонимичные термины в дискурсе молодых людей шестидесятых годов, мечтавших об «обновлении общества» и понимавших отличие своих идеалов от ценностей «старого поколения». Термин «новые люди» впервые использовал в 1860 г. Н. А. Добролюбов (1836-1861), характеризуя любовь юношей к истине: «...подросли новые люди, для которых любовь к истине и чест(С) Цой И. А., 2021

Статья открытого доступа под лицензией CC BY (https://creativecommons.org/licenses/by/4.0/) 
ность стремлений уже не в диковинку» [1, с. 299]. Молодые образованные люди читали все статьи в «Современнике», воспринимали идеи Добролюбова. Е. Н. Водовозова (1844-1923) писала, что, выйдя из Смольного института в 1862 г., она мечтала познакомиться с «новыми людьми» [2, с. 26]. Значение «шестидесятников» она видела в полезной общественной деятельности: «Весьма многие из шестидесятников так усердно работали над своим самообразованием в молодости, что, заняв впоследствии места в учреждениях по крестьянским делам, в гласном суде, в земстве, оказались чрезвычайно полезными деятелями» [2, с. 30-31]. «Люди шестидесятых годов <..> расширяли умственный горизонт русского общества» [2, с. 206]. А. А. Кропоткин (1841-1886) видел назначение молодого поколения в анализе всех событий своего времени: «..члены нашего поколения подвергают анализу предметы, <..> да здравствует холодная рассудительность нашего поколения. Старикам это чуждо...» [3, с. 93]. П. А. Кропоткин (1842-1921) считал возможным изучение "шестидесятников" по художественной литературе [4, с. 245]. С точки зрения юных интеллектуалов 1860-х гг., понятия «новые люди», «шестидесятники», «наше поколение» подчеркивали существенную роль молодежи в трансформации общества после отмены крепостного права. Выработка субкультуры «шестидесятников» шла на протяжении десятилетия и привела к расколу в молодежной среде на либералов, нигилистов и радикалов, имевших как общие взгляды на условие становления личности - свобода самоопределения, так и различия в представлениях о целях ее деятельности и методах их достижения. Одним из молодых интеллектуалов, занявших в 1860-е гг. либеральную позицию и в дальнейшем оказавших значительное влияние на образованную публику, был Василий Осипович Ключевский (1841-1911). Формирование его гражданского мировоззрения шло в 1860-е гг., со времени переезда в Москву и начала обучения в университете. Оно нашло отражение в дневниках Ключевского [5]. Анализ дневников позволяет проследить развитие его самосознания, определение им задач деятельности своего поколения.

Изучение черт личности и идейного наследия В. О. Ключевского началось в начале XX века. Авторы текстов воспроизвели факты его биографии и дали высокую оценку ему как лектору и исследователю [6]. В советской историографии анализировались фрилософские, исторические взгляды В.Ключевского[7-9]. Наиболее основательно студенческая жизнь и исследовательская работа ученого в 1860-е гг. изучена в монографии М. В. Нечкиной [10]. В современной историографии исследуется формирование и развитие «коммеморативных практик научного и культурного сообщества, посвященных В. О. Ключевскому, как воплощению “места памяти”» [11, с. 131]. По мнению О. В. Богомазовой, «чтобы понять внутренний мир историка и обусловленность оценок, которые давали ему современники, мы должны учитывать особенности формирования личности нашего героя» [12, с. 51]. «Огромным было значение личности В. О. Ключевского для его современ- 
ников. Его ценили как источник нравственности, поучительности, доброты, искрометного юмора. <.. > Ключевский как человек был самобытен и неповторим...» [12, с. 157]. Историки утверждают, что формирование мировоззрения мэтра шло в период “великих реформ», а его высшие творческие достижения принадлежали Серебряному веку русской культуры [13, с. 4]. Между тем в историографии недостаточно изучены его личные архивы, дневники, важнейшая составная часть его идейного наследия. Исследователи не выделяли проблему восприятия В. Ключевским себя как представителя поколения 1860-х гг., так что оценка его воззрения на развитие личности и общества в России этого десятилетия через себя обозначает новизну данного исследования.

Мыслящие представители молодого поколения, вступившие в самостоятельную жизнь во второй половине 1850-х - 1860-е гг., осознававшие отличительность идеалов интеллектуалов от ментальности обывателей, сорормировали свою идентичность и цели деятельности. Они считали, что должны самостоятельно определить смысл жизни, ее ценностные основы и цели деятельности.

В. Ключевский в 1861-1869 гг. вел дневник, записывая свои размышления о своей «внутренней истории», «будущей судьбе своей», о мечтаниях своего поколения, воспитании юношей, типах личности, фрактах своего времени [5, с. 278, 280, 282, 283], то есть о своих интересах и развитии общества. С помощью дневника (весьма информативного источника) представляется возможность реконструировать взгляды его автора.

В $1860-е$ гг. В. О. Ключевский размышлял о развитии личности, выявляя круг интересов своих сокурсников; он различал разные типы мировоззрений: гуманное, радикальное и обывательское - и в 1867 г. отмечал, что различия в идейном развитии молодых людей привели к расхождению дорог жизни [5, с. 283].

В. Ключевский выделял в русском обществе 1860-х гг. немногочисленный слой «высокообразованных» и «гуманно развитых» юношей, думающих о смысле своей жизни: им было сложно сохранять свои убеждения в тех исторических условиях, когда обыватели руководствовались житейскими интересами. «...Высокообразованные и гуманно развитые люди, впрочем, сохранили немногие капли этих духов в виде благородных, гуманных убеждений и идей; но жизнь безжалостно доканывает эти пузырьки, сберегаемые для освежения и подкрепления слабых голов [5, с. 282-283]. В. Ключевский использовал типизирующий подход к характеристике русского общества. Он выделял социокультурные слои, различавшиеся по своим убеждениям, характеризовал воззрение мыслящих высокообразованных людей как гуманное, благородное. По его мнению, мыслящую молодежь разочаровывала не только политика власти, но и люди, погруженные исключительно в свою обыденную жизнь, заботившиеся только о собственных интересах, следовательно не имевшие развитого гражданского сознания. 
ЦойИ. А.

Обыватели были носителями традиционных ценностей, не сознавали важности общественной деятельности. Отсутствие высших интересов у многих современников он воспринимал как неблагоприятный нравственный климат для «младенцев», молодых ищущих людей. «Между тем как дух времени, общество избивает этих младенцев, гниющих в более или менее возвыиенных мечтах о будущих лучших временах,

...Когда народъ, распри позабъь,

В великую семъю соединятся!» [5, с. 283].

Историк нравственно дистанцировавшийся от духовного мещанства, будучи глубоко рефрлексирующей личностью, находил поэзию «в раздумъе человека о будущей судъбе своей» [5, с. 283].

В 1861-1865 гг. В. Ключевский учился в Московском университете и полагал, что молодые люди в начале 1860 -х гг. еще недостаточно хорошо ориентировались в общественных отношениях. Особенностью юношеского взгляда на мир он считал неясность дум и мечтаний, «как умеет мыслить только юность, незнакомая с разделениями и определениями» [5, с. 283]. По его мнению, человек в юности пробирается к самопознанию «извилистыми тропами», сомневаясь, надеясь, находится перед выбором жизненного пути и с тревогой «смотрит в туманную даль. Все есть в этой думе, и трудно сказать, чего больше - мысли, сердца, франтазии и старания обмануть себя или другого» [5, с. 267].

Высокообразованные молодые люди стремились понять смысл своей жизни и общественного развития. В 1861 г. в дневнике В. Ключевский размышлял о своем нравственном и интеллектуальном выборе, записывал «выношенные и выдержанные думы», которые он назвал «нравственным капиталом». ». В дневнике - «приходной книге души» [5, с. 279-280] - он подвергал всесокрушающей силе анализа все, о чем думал, стремясь к «пытливому исследованию» своего внутреннего мира [5, с. 267-268. «Жиинь или ничтожество», - так он сформулировал свой жизненный выбор в 1861 г. [5, с. 268]. Чем должна быть заполнена жизнь? «Здравое сознание», мечта о «несбыточном счастье»; стремление «безотчетно и безраздельно отдаться науке», закрыв глаза на современность, но не из страха перед действительностью; желание приобрести знания [5, с. 268, 270] - элементы рефлексии присутствуют в целях деятельности двадцатилетнего Ключевского. Важно отметить высокий уровень идейно-нравственного поиска юноши, понимавшего, что ясное самосознание - залог правильного понимания смысла его жизни. Ее содержание он находил в интеллектуальном труде.

С точки зрения молодого человека, высокая самоотдача в научной сфере не позволяет человеку забыть свою гражданскую позицию. Нужно знать актуальные проблемы жизни общества, иметь собственное суждение о происходивших в стране событиях и процессах: «...можно ли спокойно оставаться и смотреть, <...> когда неотступно, со всей силой тянут к себе эти 
вопросы, глухо, но сильно раздающиеся из-под маскированной, а подчас и не замаскированной речи? И готов сказать себе: стыдно оставаться глухим при этом родном споре, стыдно не знать его» [5, с. 270]. «Родной спор»дискуссия интеллектуалов, начавшаяся на рубеже 1830-1840-х гг., о судьбе России, идейно-нравственных основах ее цивилизационного развития. В. Ключевский понимал значение этого интеллектуального спора: он был необходим самоопределяющемуся обществу, ищущему ответы на многие насущные вопросы. С его точки зрения, наука не должна «заколачивать ухо от всего, что творится и шумит перед тобой» [5, с. 270]. Удивительно, по его мнению, когда известные литераторы «не знали ... современной жизни и ее стремлений и надежд» [5, с. 270]. В его дневниковых записках преобладала духовно-нравственная проблематика, размышления о выборе судьбы.

Огромную роль в пробуждении интереса молодежи к насущным вопросам жизни с конца 1850-х годов играли журналы. В столицах и провинции молодые люди читали преимущественно «Отечественные записки», «Современник», «Русский вестник»: «..стоит заглянуть в какой-нибудь из живых, немногих наших журналов, <..> стоит встретиться только с этими речами и вопросами, чтобы увлечься ими и забыть мирную книгу» [5, с. 270]. С его точки зрения, журналистика побуждала молодых людей к обсуждению насущных проблем российской действительности. Современные задачи общества требовали разрешения, считал В. Ключевский, следовало иметь «твердое верование, неотступно влекущее к делу» [5, с. 270]. Он полагал, что надо принадлежать «к какому-нибудь лагерю» [5, с. 270]. Нужна деятельность с целью преобразования общества, человек должен найти в себе интеллектуально-нравственные силы и энергию.

В 1862 г. ему представлялось, что мыслящие люди, авторитетные в обществе, должны соединиться «в дружный протест» и заявить «решительно, что все стоят за дело правды» [5, с. 270]. Поиск правды жизни и методов ее торжества должен увлечь мыслящих людей, обязанных размышлять над актуальными вопросами жизни. Студент Ключевский был более склонен к кабинетной умственной деятельности в уединении, вызывавшей у него вдохновение. Он хотел «замкнуться от всего», тяготел к саморедлексии, чтобы похвастаться «внутренним довольством» [5, с. 271]. Он фрормировал свою личность, развивал свое мышление, набирал знания, чтобы стать профессионалом в своем деле. «Свободное участие» в жизненных «комбинациях» - позиция человека, размышлявшего над вопросом, на что должны быть потрачены «силы молодости» [5, с. 272]. Молодого Ключевского привлекала самостоятельная деятельная жизнь, интересовала проблема личности и ее роль в общественной жизни.

Идейно-ценностная основа его жизненного выбора - отражение мотивации интеллектуалов 40-х гг. XIX в. - может рассматриваться как результат восприятия высоких заповедей московской профессоры того времени. 
ЦойИ. А.

Высокий профессионализм, присущий времени великого спора о судьбе России, и вовлеченность в обсуждение актуальных проблем общества важнейшие знаковые черты умственной и социальной культуры, унаследованные интеллектуалом В. Ключевским, одним из наиболее одаренных «шестидесятников".

По его мнению, каждый молодой человек стоит перед выбором жизненного пути, зависящего от миросозерцания. Первая дорога есть дорога «пассивного, послушного следования за другими. Другая, направо, есть дорога насилия, фризического, умственного или нравственного - все равно, дорога людей, стремящихся вести других за собой, давать им тон, вертеться впереди, импонировать...» [5, с. 284]. В. Ключевскому одинаково чуждо было подчинение и насилие. Он выбрал путь самостоятельной, свободной деятельности без давления на других лиц и самоуничижения.

В 1867 г. историк писал о разочаровании и в политике государства, и в бездеятельной позиции общества.

Размышления о своей судьбе и основах жизни общества, обеспечивавших его устойчивое цивилизационное развитие, - задача мыслящих людей, считал молодой Ключевский в 1868 году [5, с. 286]. Люди должны стремиться к «осознанию себя самих, ясному взгляду на настоящее». Этому может способствовать и понимание истории общества, поскольку социум несет к себе тяжелые влияния эпох, включая современную [5, с. 286]. Он полагал, что прежде всего надо понять «интересы текущей жизни», проанализировать опыт преобразований, тогда можно осознать «начала» развития и его итоги, соответствие результатов целям трансформаций. «Готовая проверка этого развития» позволяет осмыслить верность выбранных начал, принципов движения.

Не только внешние обстоятельства, определяемые государством, влияют на судьбу человека и общества. Следует самим менять «понятия, ... принципы», на основе которых они живут. Важно осознать, что народная жизнь должна иметь «некоторые начала», «основные условия развития». Условия движения общества надо ценить как «лучшие человеческие блага». Ученый признавал верными идеи своих предшественников и современников, что лучшими благами, основами жизни являются законность, дающая человеку чувство защищенности своей жизни юридически обеспеченными правами, и свободомыслие индивида. Он писал: «...начала привыкли сводить к двум главным: чувству законности, права в мире внешних отношений и к деятельной мысли в индивидуальной сфрере» [5, с. 286]. Законность, права человека, свобода мысли обеспечат обществу прочное развитие, его будущее. «В развитии и упрочении этих благ все наше будущее, все наше право на существование» [5, с. 286]. Основания жизни общества должны быть укоренены, стать «руководящей нитью, маяком» его движения, и тогда рассеется «сумрак», ясна будет цель и гарантированы условия развития личности. «Никто не может сказать, что из нас выйдет в далеком более или ме- 
нее будущем. Но мы знаем, что из нас ничего не выйдет, если мы не усвоим себе этих элементарных оснований всякой истинно человеческой жизни. Вот наша руководящая нить, маяк, который мы не можем выпускать из вида...» [5, с. 286].

Молодой Ключевский считал, что исторический процесс не запрограммированный, но его движение обеспечивают определенные начала, принципы, обстоятельства. Если думать об интересах человека, то надо и выбирать начала, гарантировавшие ему право на свободное развитие и самореализацию.

В конце 1860-х гг. мысль ученого о сущности движения общества стала ясной, он имел свое понимание смысла своей жизни и принципов гуманизации общественных отношений. Одна из причин, повлиявшая на пессимистическое восприятие Ключевским людей своего времени, - жестокие внешние обстоятельства. «Тоскливо, грустно отзываются во мне звуки жизни. Сколько в них негармоничного, жестокого!» [5, с. 279].

Согласно самооценке, «внутренний слух» В. О. Ключевского был восприимчивым. Он искал своего личного спасения в позиции «безучастного наблюдателя» и в труде: «Труд заглушает во мне эти отзывы, полные боли» [5, с. 279]. Юный Ключевский хотел попросить у Бога «сохранения хоть капли веры в людей, следовательно, и в себя» [5, с. 279].

В 1860-е гг. ему, по его словам, удалось нарастить свой интеллектуально-нравственный капитал. Он сознательно работал над формированием своей системы ценностей: «Много нравственных ценностей, не достававших у меня, стремился я приобресть...», он стремился к нравственной устойчивости, развитию самосознания [5, с. 280]. Так он создавал свой «внутренний мир», «которого так жадно ищешь и просишь у судьбы» [5, с. 280-281]. Молодой человек сознательно творил «внутреннюю историю», анализируя свои ощущения, мотивы, настроение, интересы, стремления, взгляды на жизнь.

Мыслящие «шестидесятники» свое участие в преобразовании общества видели в воздействии на его интеллектуально-нравственное развитие.

В. О. Ключевский, став в двадцать четыре года профессиональным историком, в середине 1860-х гг. считал, что в обществе есть сознательные силы, они ведут борьбу с бессознательными. Следовательно, нужно развивать сознание людей. Реальной целью процесса может стать создание в будущем «благоустроенного государства» и «свободной личности». В настоящей действительности есть лишь “слабые признаки» достижимости этой цели [5, с. 292].

В историческом процессе молодой историк выделял два противоположных начала - государство, представленное правительством, с претензией к благосостоянию и «личность с своими воспаленными мечтами о свободе». Это противостояние было вызвано стремлением представителей власти обеспечить себе «благоустройство» за счет «справедливости и свободы» 
ЦойИ. А.

человека. Личность раздражена постоянными оскорблениями, произволом и ограничением ее прав. В. О. Ключевский понимал, что насильственные методы с обеих сторон неизбежны. И если власть готова действовать «ценою страшных жертв», то личность готова «разрушить, по-видимому, самые необходимые основания человеческого общества», их жизнь одинаково проникнута «духом насилия» [5, с. 292-293].

В. О. Ключевский писал, что личность не должна руководствоваться только мечтой о свободе. Он полагал, что необходимо людям «учиться разумно жить друг с другом» [5, с. 293]. Эта цель настоящей и будущей жизни общества. Необходимо развивать «способность человека правильно понимать и осуществлять свои отношения к человеку» [5, с. 293]. Движение должно быть «разумным».

Молодой историк сорормулировал реалистическую задачу современного общества, решение которой обеспечивало устойчивое цивилизационное развитие России, - учиться «разумно», благородно, с уважением выстраивать людям свои взаимоотношения. Он полагал, что молодое поколение обязано “разумно» понять смысл своей деятельности.

Понятие «разумность» - одно из ключевых в дискурсе ученого. Он употреблял его в контексте размышлений о типе мышления, взаимоотношениях между людьми, направлении движения общества. Ему была несвойственна идеализация общественных отношений. Он полагал, что идея защиты прав человека завоевывала умы людей. «Никогда личность не чувствовала так сильно свои права...» [5, с. 295].

Как видно, молодой Ключевский в 1860-е гг. думал о своем интеллектуально-нравственном развитии и об идейной жизни своего поколения. С его точки зрения, молодые люди в начале 1860-х гг. были мечтателями, надеялись на быстрое переустройство общества на основе идей социального равенства. Однако медленное преобразование социальных отношений стало одной из причин разочарования очень многих людей в политике власти. Ученый выделял группу молодых людей, сориентировавшихся на гражданскую деятельность в социокультурной сорере. По его мнению, другие довольствовались мещанским идеалом сытой личной жизни, а третьи выбрали радикальные методы перестройки страны. Ключевский даже эпоху «Великих реформ», расширивших свободу человека в России, считал сложным временем для самореализации интеллектуалов. В его представлении большинство людей не рефлексировали на тему духовно-нравственного, интеллектуального развития, жили в соответствии с устоями, а изменить их взгляды на жизнь было либо сложно, либо невозможно. Свой жизненный выбор он определил как формирование гражданского сознания молодых людей через преподавательскую и научную деятельность. Он не хотел замыкаться только на частной жизни. Молодому Ключевскому было присуще чувство времени - понимание, что реализовывать потребности можно в конкретных жизненных условиях. Он был реалистом 
и сорормулировал устремления молодых интеллектуалов: самосознание, «жизненное дело» в интересах общества, верность принципам, приобретение научных знаний. Саморефлексия и умственный труд, выработка устойчивой системы ценностей рассматривались В. О. Ключевским как путь самосознания и становления личности.

\section{Ссылки}

1. Добролюбов Н. А. Когда же придет настоящий день? // Добролюбов Н. А. Вопросы, заданные жизнью. М.: Сов. Россия, 1986. С. 294-342.

2. Водовозова Е. Н. На заре жизни. Мемуарные очерки и портреты: в 2 т. М.: Художественная литературы, 1987. Т. 2. 527 с.

3. Переписка Петра и Александра Кропоткиных: в 2 т. М.; Л.: Академия, 1932. T. $1.278 \mathrm{c}$.

4. Кропоткин П. А. Записки революционера. М.: Моск. рабочий, 1988. 544 с.

5. Ключевский В. О. Дневники и дневниковые записки // Ключевский В. О. Сочинения: в 9 т. М.: Мысль, 1990. Т. IX . С. 267-298.

6. Ключевский В. О. Характеристики и воспоминания. М.: Научное слово, 1912. 217 c.

7. Киреева Р. А. В. О. Ключевский как историк русской исторической науки. М.: Наука, 1966. 230 с.

8. Чумаченко Э. Г.В.О.Ключевский - источниковед. М., 1970. 224 с.

9. Карагодин А. И. Философрия истории В. О. Ключевского. Саратов, 1976.73 с.

10. Нечкина М. В. Василий Осипович Ключевский. История жизни и творчества. М., 1974. 640 с.

11. Богомазова О. В. Между памятью и забвением: практики увековечивания В. О. Ключевского в культуре России XX - начала XXI века // В. О. Ключевский: воспоминания и исследования. СПб.: Изд-во Политехнического университета, 2017. C. $131-158$.

12. Богомазова О. В. Частная жизнь известного историка (по материалам воспоминаний о В. О. Ключевском // Вестник Челябинского государственного университета. 2009. № 23 (161). История. Вып. 33. С. 151-159.

13. Малинов А. В. К юбилею памяти В. О. Ключевского // В. О. Ключевский: воспоминания и исследования / отв. ред. А. В. Малинов. СПб.: Изд-во Политехнического университета, 2017. С. 3-7. 